\title{
The relationship between attitudes toward the teaching profession, occupational resilience belief, and extra-role behavior: A moderated mediation model
}

\author{
Kürşad Kara ${ }^{1}$ and Kübra Ada ${ }^{2}$ \\ ${ }^{1}$ Bayburt University, Faculty of Education, Turkey (ORCID: 0000-0002-8190-5180) \\ ${ }^{2}$ Bursa Uludă̆ University, Institute of Educational Sciences, Turkey (ORCID: 0000-0001-6243-9703)
}

\begin{abstract}
This study aims to examine the direct and indirect relationships between pre-service teachers' attitudes toward the teaching profession, their occupational resilience beliefs, and their tendency to engage in extrarole behaviors within the framework of structural equation modeling. A relational survey model was used to design this quantitative investigation. The sample comprises 430 pre-service teachers who enrolled at four different programs at a state university in Turkey. The study used the attitudes toward teaching profession scale, the occupational resilience beliefs scale for pre-service teachers, and the extra-role behaviors scale (teacher form) as data collection tools. The researchers created hypothesis models examining the mediating and moderated mediating role of the occupational resilience belief in the effect that attitudes toward the teaching profession have on extra-role behaviors and tested these models within the framework of structural equation modeling. As a result of the study, it was found that the relationship strength between the attitudes toward the teaching profession, the occupational resilience belief, and extra-role behaviors was moderate. The study determined that occupational resilience belief plays a mediating role in the effect of pre-service teachers' attitudes toward the teaching profession on extra-role behaviors. According to the results of the moderated mediation analysis, the influence of this indirect effect on extra-role behaviors varies according to the type of program studied, even though it does not differ significantly according to the class level of the pre-service teachers. This indirect effect is provided at the best level for pre-service teachers in the mathematics education program. However, the study concluded that the indirect effect influence significantly weakened in the Turkish education program.
\end{abstract}

Keywords: Attitudes toward the teaching profession; Occupational resilience belief; Extra-role behavior; Mediator effect model; Moderated mediation model

Article History: Submitted 17 February 2021; Revised 1 August 2021; Published online 18 August 2021

\section{Introduction}

Teachers engage in extra-role behaviors are vital for schools to fulfill their goals and achieve the expected success (Runhaar, et al., 2013; Somech \& Ron, 2007). Since the individual's attitude

Address of Corresponding Author

Kübra Ada, Mathematics Education Doctorate Program, Institute of Educational Sciences, Bursa Uludağ University, 16120, Bursa, Turkey.

$\triangle$ kubrada.16@gmail.com

How to cite: Kara, K. \& Ada, K. (2021). The relationship between attitudes toward the teaching profession, occupational resilience belief, and extra-role behavior: A moderated mediation model. Journal of Pedagogical Research, 5(3), 105-121. https:// doi.org/10.33902/JPR.2021371258 
towards a stimulus is a very important determinant of the person's behavior towards the stimulus in question, it can be said that the tendency to engage in non-role behaviors is significantly affected by the individual's attitude towards his profession and his belief in professional resilience (Üstüner, 2006). Additionally, any change in an individual's attitude can change the relationship between that person's beliefs and behaviors (Çapri \& Çelikkaleli, 2008). The individual's positive attitude and subjective well-being lead the individual to resilience and positive behavior. This situation can be associated with positive psychology. Positive psychology is driven by the mission of using scientific methodology to discover and develop processes and conditions that contribute to the functioning and development of individuals, groups and institutions (Gable \& Haidt, 2005; Luthans, 2002a). The two main areas that positive psychology focuses on include positive individual characteristics such as an individual's abilities and interests, and positive institutions such as schools and businesses. Positive individual characteristics include subjective well-being, perseverance at the individual level, high ability and virtue. Positive organizational characteristics include behavioral characteristics such as responsibility, self-sacrifice, resilience and work ethic (Luthans, 2002b). Addressing these issues, positive psychologists focus on investigating individuals' strengths, attitudes, and their impact on beliefs, effectiveness, and productivity (Woolfolk-Hoy et al., 2008).

Accordingly, it is predicted that a teacher who exhibits a positive attitude toward their profession has a strong occupational resilience belief against difficult conditions (Dönmez \& Karasulu Kavuncuoğlu, 2019) and thus displays behaviors beyond the role expected of them. However, in the literature, no study examines the relationship between these three variables within the framework of a structural model holistically. This situation has led us to create a model that will establish the link between attitudes toward the profession and extra-role behaviors. In this context, the study conceptualized based on the positive psychology approach a model in which occupational resilience belief mediates the relationship between attitudes toward the teaching profession and extra-role behaviors. It is believed that the structural model revealed in the research will significantly contribute to the determination and planning of the steps to be followed to increase the tendency to perform extra-role behaviors.

\subsection{Theoretical Framework}

\subsubsection{Attitudes toward the teaching profession}

One of the professions required in the educational stages for the development of societies is teaching. Teaching is a profession that requires expertise in a field and certain training (Akbaşl1, 2009). Teachers, who have a great influence on and role in the development of students' cognitive, affective, and behavioral characteristics, should have a strong and positive attitude toward their profession (Blazar, 2018; Chakraborty \& Mondal, 2014). Teachers' attitudes toward their professions are generally related to their love for their profession, their commitment to their profession, and their awareness that their profession is necessary and valuable socially (Ay1k \& Ataş, 2014).

As one of the important elements of affective characteristics, attitudes are frequently discussed in educational research (Jahan, 2017; Melki \& Bouzid, 2021). As attitudes are one of the determinants of behavior when examining individuals' actions, they are considered worthy of research and investigation (Ajzen \& Cote, 2008). Attitude is a person's tendency to react positively or negatively to someone or something (Mazana et al., 2019). In the Dictionary of Education, attitude is defined as learned tendencies that push individuals to demonstrate certain behaviors in the face of certain people, objects, and situations (Demirel, 2003). Therefore, attitude leads individuals to certain behaviors when confronted with people, objects, and situations (Demirel \& Ün, 1987). Morris (1995/2002) mentioned that attitude has three components: thought, emotion, and behavior. In this respect, professional attitude also shapes the teacher's thoughts, feelings, and behaviors. In short, knowing what the attitudes of teachers are is significant in determining what their behavior will be (Üstüner, 2006). For this reason, the learning experiences of pre-service 
teachers should be arranged in a way to create positive attitudes toward the teaching profession (Coşkun, 2011). If pre-service teachers are trained with positive attitudes toward their profession, they can exhibit more positive behaviors toward students when they become teachers (Çeliköz \& Çetin, 2004). Therefore, in teacher education, in addition to features such as field knowledge, professional knowledge, and general culture, teachers' attitudes toward the profession should be taken into consideration (Coşkun, 2011; Çeliköz \& Çetin, 2004) and efforts should be made for preservice teachers to exhibit positive attitudes toward the teaching profession. In fact, Üstüner (2006) stated that teachers should have a positive attitude toward the teaching profession in order to fulfill their professional roles and duties more effectively. Teachers with a positive attitude focus on active performance and self-improvement rather than being dormant in their professional lives. Accordingly, they do not see stressful life circumstances in the work environment as an obstacle and turn these situations into opportunities for their personal development (Maddi et al., 2009).

\subsubsection{Extra-role behavior}

There are also some official roles and duties identified for the teaching profession, and teachers are expected to fulfill these duties in the education process. The concept of role is defined as the legitimate behavior patterns that someone who occupies a position in the social unit should perform depending on this position (Robbins \& Judge, 2006/2012). An employee exhibits two types of behaviors within an organization: first, role behaviors stipulated by the legislation related to the work done, and the second is self-sacrifice based extra-role behaviors (Aktan, 2015). In summary, extra-role behaviors are voluntary behaviors that are not assigned as an official duty.

Schools need teachers to demonstrate voluntary behaviors beyond their official duties to achieve their goals (Runhaar et al., 2013), because when encountered with unexpected situations in schools, teachers must behave beyond what is expected of them to reach the determined goals. Therefore, it is expected that an institution that operates solely based on law-bound codes of conduct will turn into a fragile social system (Katz \& Kahn, 1966/1977). As a matter of fact, Somech and Ron (2007) stated that the voluntary actions of teachers outside of their defined duties have a crucial effect on the success of schools. The success of schools mainly depends on the willingness of the teachers. To realize institutional goals, there is a need for employees who engage in discretionary behaviors beyond their role requirements, and therefore, having many precursors that affect these behaviors becomes even more relevant (Kalmaz \& Tozkoparan, 2020). Willingness in teachers comes to the fore as extra-role behaviors such as helping students and colleagues, totally committing to the school, and avoiding wasted learning time (Oplatka \& Golan, 2011). Such extra-role behaviors also increase the teacher's sense of belonging to the institution he/she works in and keeps the teacher's motivation at high levels regardless of the conditions.

\subsubsection{Occupational resilience belief}

Occupational resilience in teachers refers to their belief that they can adapt to the difficult conditions of the teaching profession, cope with obstacles, and maintain their commitment to the profession (Tagay \& Demir, 2016). In psychologically resilient teachers, it has been observed that features such as having a positive attitude toward the teaching profession and being satisfied with being a teacher; being patient, optimistic, determined, and decisive in their profession (Sezgin \& Ada, 2018), dealing with difficulties in a healthy way, taking responsibility, problem-solving, and making plans (Tait, 2008) come to the fore. The professional performances of teachers with these characteristics will also improve.

The positive attitude toward the profession and the extra-role behaviors demonstrated are of great importance, because teachers can sometimes work in difficult environmental conditions with limited resources. It is difficult for a teacher who is under intense pressure in their professional life to perform well (Dönmez \& Karasulu Kavuncuoğlu, 2019). This situation requires teachers to demonstrate occupational resilience against difficulties to fulfill their duties. In this context, it is important to increase teachers' tendency for extra-role behaviors and occupational resilience beliefs to improve the quality of education in schools and their performance (Maddi, 2002). 
In the literature, these three variables, extra-role behaviors (Srivastava et al., 2019), the occupational resilience belief (Bowles \& Arnup, 2016; Dönmez \& Karasulu Kavuncuoğlu, 2019; Malcom, 2007), and the attitude toward the teaching profession (Abshir, 2020; Jahan, 2017; Melki \& Bouzid, 2021) were analyzed separately. At the same time, it was determined that there are significant relationships between these variables (Dönmez \& Karasulu Kavuncuoğlu, 2019; Maddi, 2002). However, no study was found that examines the relationship between these three variables within the framework of a structural model holistically. However, to increase pre-service teachers' tendency to exhibit extra-role behaviors, it is necessary and relevant to examine these concepts together and to investigate the relationship between them in a holistic manner. Hence, it was determined in the studies conducted that positive attitudes toward the teaching profession strengthen the belief in occupational resilience (Dönmez \& Karasulu Kavuncuoğlu, 2019) and individuals with a high occupational resilience belief fulfill their duties and responsibilities more (Beltman et al., 2011; Knight, 2007; Maddi, 2002). In this regard, it is predicted that a positive attitude toward the teaching profession will increase teachers' tendency to display extra-role behaviors by strengthening their occupational resilience beliefs. Therefore, within the scope of the study, the aim was to test the structural model that examines the mediating role of the occupational resilience belief in the effect of attitudes toward the teaching profession on extra-role behaviors. Thus, it is believed that the mediator effect model put forward will clarify the steps to be followed to increase the tendency to perform extra-role behaviors and will lay the groundwork for the studies to be carried out.

Determining in which situations the indirect effect in the proposed structural model is stronger or weaker is also crucial for future studies and activities on the subject, because the power of the mediator effect model may differ in pre-service teachers studying in different teaching programs. Similarly, the model put forward may have a greater effect at certain class levels of the pre-service teachers. It is also within the scope of the study to determine whether the mediator effect model proposed in this context shows contingency according to the class level and program type of the pre-service teachers. Thus, the findings of the study will be a significant guide in designing the vocational education process to increase the pre-service teachers' tendency to demonstrate extrarole behaviors. Although some structural models have been revealed in studies on extra-role behaviors in the literature (Bozali 2017; Van Loon et al., 2017), there are no studies that examine how the indirect effect influence in these models varies in which situations. In this regard, it is believed that the study has a unique value both in terms of the structural model presented and the methodology used.

\subsection{The Aim}

The aim of this study is to examine the direct and indirect relationships between pre-service teachers' attitudes toward the teaching profession, their occupational resilience beliefs, and their tendency to engage in extra-role behaviors within the framework of structural equation modeling. At the same time, it was aimed to determine the indirect effect influence in the model presented according to class level and program type. In line with these purposes, the following hypotheses were tested within the scope of the study.

H1: There is a significant relationship between pre-service teachers' attitudes toward the teaching profession, occupational resilience beliefs, and extra-role behaviors.

H2: Pre-service teachers' occupational resilience beliefs have a mediating role in the relationship between their attitudes toward the teaching profession and their extra-role behaviors (see Figure 1)

H3: In the indirect effect of pre-service teachers' attitudes toward the teaching profession on their extra-role behaviors through their occupational resilience beliefs,

H3a: The program type has a moderator effect.

$\mathrm{H} 3 \mathrm{~b}$ : The class level has a moderator effect (see Figure 3). 
Figure 1

The Mediator Effect Hypothesis Model (H2)

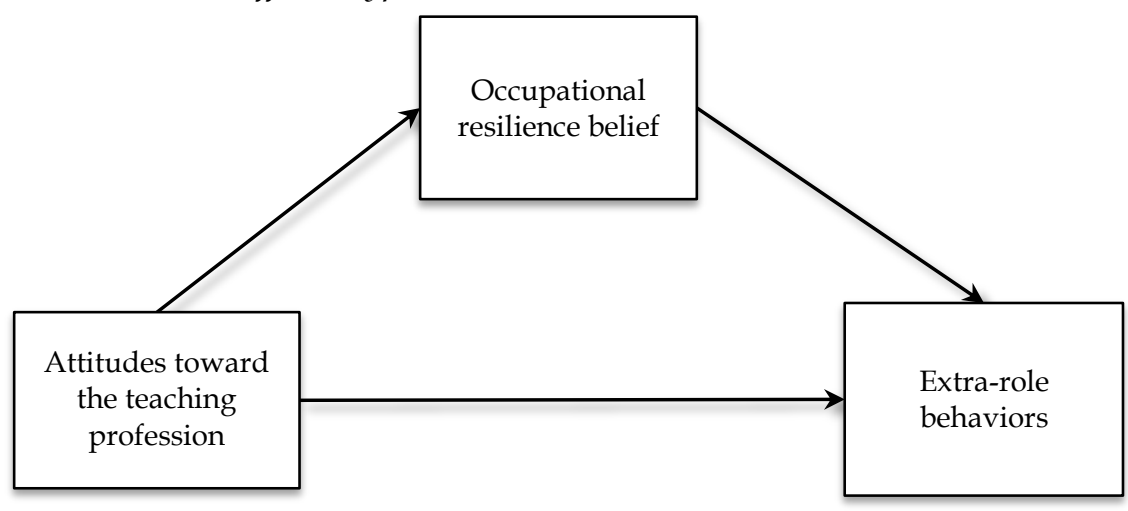

Figure 2

The Moderated Mediator Effect Hypothesis Models (H3)

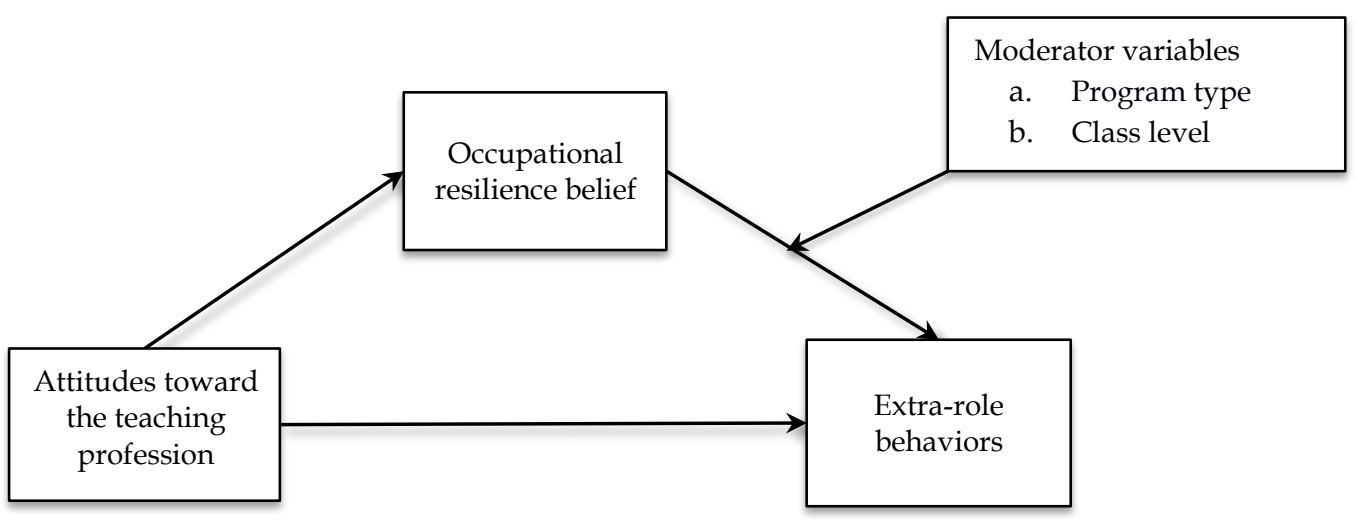

\section{Method}

\subsection{Research Model}

This research is a quantitative study designed with a relational survey model. Relational survey models aim to determine the existence and degree of covariance between two or more variables (Karasar, 2016). As the aim of the study is to examine the mediating and moderated mediating role of the occupational resilience belief in the relationship between the attitude toward the teaching profession and extra-role behaviors, it is necessary to present causal relationships, mediation, and moderation effects. For this reason, the study used the relational screening model, which includes the structural equation model, and the hypothesis models were tested within the framework of the structural equation modeling. Structural equation modeling is a method used in examining the causal relationships between variables and testing complex models with mediator-moderator variables (Gunzler, Chen, Wu \& Zhang, 2013).

\subsection{Study Group}

The study population comprises 430 pre-service teachers studying in 4 different programs in a state university in Turkey. The quota sampling method was used in determining the sample. In this sampling method, the population is divided into groups according to certain characteristics in line with the purpose of the research. Then, the ratios of these groups in the research population are determined and the subjects to be included in the sampling are selected based on this percentage. Thus, it is ensured that the individuals sampled are the same or close to the group percentages in the research population (Yang \& Banamah, 2014). 
In this study, the groups in the population were reviewed under the categories of "program" and "class level" by also taking into account the research problem. The groups in the program category are the mathematics education, Turkish education, psychological counseling and guidance (PCG), and classroom education departments. The groups in the class level category are freshmen, sophomore, junior, and senior. In the process of sample selection from the population, the group ratios of these two categories and the voluntary participation criteria of the subjects were taken into account. In this context, an online questionnaire was sent to each of the pre-service teachers studying in four different departments and at four different class levels. Thus, all individuals' probability of being selected for the sampling from the population was kept equal, but only individuals who voluntarily participated were included.

The distribution of the determined sample according to the program and class levels shows a similar distribution (same or close values) with the ratios of these categories in the population. Of the participants, $23 \%$ study in "mathematics education", $22 \%$ in "Turkish education", $28 \%$ in "PCG", and $27 \%$ in "classroom education". When the distribution according to class level was examined, from the freshmen $(n=134)$, the sophomores $(n=107)$, the juniors $(n=93)$, and the seniors $(\mathrm{n}=96)$ participated in the study. Additionally, the distribution of each program in the sample according to class levels was also taken into consideration and it was determined that it was significantly coherent with the distribution in the population. In this respect, it can be said that the sample determined has a high probability to represent the population.

\subsection{Instruments}

This study used the attitude toward the teaching profession scale, the occupational resilience belief scale for pre-service teachers, and the extra-role behaviors scale (Teacher Form) as data collection tools.

\subsubsection{Attitudes toward the teaching profession scale}

The attitude toward the teaching profession scale developed by Üstüner (2006) aims to determine the attitude of students studying in teaching programs toward the teaching profession. The scale comprising 34 items is a one-dimensional, 5-point Likert-type attitude scale. As a result of the principal components analysis conducted regarding the construct validity of the scale, it was seen that the item factor load values ranged from .74 to .41 . The criterion scale validity was calculated as .89. In the reliability analysis of the scale, the reliability coefficient for the stability of the scores was .72 , and the internal consistency coefficient was .93 (Üstüner, 2006). This scale was preferred as a data collection tool in the study as it was developed to measure the attitudes of pre-service teachers toward the teaching profession, as well as the fact that the items of the scale were clear and understandable and because of its high validity and reliability.

To verify the construct validity of the scale, a confirmatory factor analysis (CFA) was performed using the AMOS 24 program. As one of the most frequently used indexes in the interpretation of analysis results, the $x 2 / S D$ value being less than 3 means a good fit and less than 5 means an acceptable fit (Sümer, 2000). The RMSEA value and RMR value being .08 or less and the CFI and GFI values being .90 and higher indicates a good fit (Brown, 2006; Hooper et al., 2008; Sümer, 2000). In this context, according to the fit indexes calculated as a result of CFA in the study, it can be said that the model shows an acceptable fit with the data $\left(\chi^{2}=1184.751 ; \mathrm{p}<.001 ; \mathrm{SD}=519\right.$; $\chi 2 / \mathrm{SD}=2.283 ; \mathrm{RMSEA}=.076 ; \mathrm{CFI}=.85 ; \mathrm{RMR}=.057)$. Additionally, the internal consistency Cronbach Alpha coefficient of the scale was calculated as .95.

\subsubsection{The occupational resilience belief scale for pre-service teachers}

The occupational resilience belief scale for pre-service teachers developed by Tagay and Demir (2015) is a one-dimensional scale consisting of 26 items. The validity and reliability studies of the scale were carried out on pre-service teachers, and it was determined that the one-factor structure of the scale has good fit indexes. In the reliability studies of the scale, the Cronbach Alpha internal consistency coefficient was found as .93. In the test-retest reliability study, the Pearson correlation 
coefficient between the scores was calculated as " $r=.76$ " (Tagay \& Demir, 2015). In the literature, scales developed to measure the occupational resilience of pre-service teachers are limited in number, and as this scale has high validity and reliability, it was used as a data collection tool within the scope of the study.

The single-factor structure of the scale was verified by performing a CFA. The fit indexes obtained for the model indicate that the model fits well with the data $(\chi 2=590,997 ; \mathrm{p}<.001 ; \mathrm{SD}=$ 294; $\chi 2 / \mathrm{SD}=2.010 ; \mathrm{RMSEA}=.068 ; \mathrm{CFI}=.91 ; \mathrm{RMR}=.038)$. The internal consistency Cronbach Alpha coefficient of the scale was calculated as 95 .

\subsubsection{The extra-role behaviors scale (Teacher form)}

The extra-role behaviors scale (teacher form) developed by Güner Demir (2015) is a 5-point Likerttype scale consisting of 16 items. This scale, which has a two-factor structure, consists of items related to "supportive extra-role behaviors" and "intrusive extra-role behaviors" dimensions. It was determined that the factor load values of the items in the supportive extra-role behaviors dimension of the scale varied between .78 and .57, and the Cronbach Alpha reliability coefficient was calculated as .91 . The factor load values of the items in the intrusive extra-role behaviors dimension of the scale varied between .77 and .38, and the Cronbach Alpha reliability coefficient was calculated as .75 (Güner Demir, 2015). In the literature, no scale was found that was developed to measure pre-service teachers' tendency toward extra-role behaviors, according to this research, and scales developed/adapted for teachers are quite limited. The scale was used as a data collection tool in the study because of its high validity and reliability, the expert opinion received, and the fact that the items of the scale were appropriate, clear, and understandable for determining the extra-role behavior tendencies of the pre-service teachers.

Güner Demir (2015) carried out this scale development study on classroom teachers. To measure whether the factor structure of the extra-role behaviors scale is suitable for the data set of this research, first, an exploratory factor analysis (EFA) of the scale was conducted within the scope of the study. For the EFA examination of the pre-service teachers, it was determined that the scale data were suitable for EFA by calculating, first, the Kaiser-Meyer-Olkin coefficient (.91) and the Bartlett's Sphericity test $\left(\chi^{2}=2317.98, p<.001\right)$. For the EFA, the "Promax" procedure, one of the Oblique Rotation methods, and the Basic Components Analysis was applied. According to the analysis result, it was determined that the scale has a two-factor structure and represents $53.64 \%$ of the total variance. In addition, it was determined that the factor load value of each item in the scale was above .32 and each item was loaded on its own factor. The factor load values of the "supportive extra-role behaviors" dimension, which is one of the sub-dimensions of the scale, vary between .52 and .80 , and factor load values of the "intrusive extra-role behaviors" dimension vary between .61 and .86. After the EFA examination of the scale, a CFA examination was also performed to confirm the determined factor structure. For this, an examination was conducted on a group other than the study group used in the EFA. In this context, according to the fit indexes obtained as a result of the CFA of the scale, it was determined that the model fit well with the data $\left(\chi^{2}=192.907 ; p<.001 ; \mathrm{SD}=101 ; \chi^{2} / \mathrm{SD}=1.910 ; \mathrm{RMSEA}=.064 ; \mathrm{CFI}=.94 ; \mathrm{RMR}=.040 ; \mathrm{GFI}=.91\right)$. Additionally, the Cronbach Alpha reliability coefficient of the scale was calculated as 89 .

\subsection{Data Analysis}

In the analysis of the data, first, missing data or incorrect coding cases in the data set were examined. Then, a one-way and versatile extreme value analysis was conducted for all continuous variables within the scope of the study. As a result of the one-way extreme value analysis, nine observations with extreme values were removed from the data set. In the versatile extreme value analysis, the Mahalanobis distance values were calculated and 10 observations with extreme values were removed from the data set. In this context, univariate and multivariate normality cases were examined in the 430 observations remaining. It was determined that the Skewness and Kurtosis coefficients for all continuous variables in the data set had values between " -1 " and " +1 " and the arithmetic mean mode and median values for each variable were close to each other. In the 
case of univariate normality, the Skewness and Kurtosis coefficients being between " -1 " and " +1 " (Çokluk et al., 2016, p. 16) and the fact that the arithmetic mean, mode, and median values for each variable are equal or close to each other (Tabachnick \& Fidell, 2001) indicate the existence of a normal distribution. In this regard, it can be said that the observations of the variables show a univariate normal distribution statistically. The Scatter Plot Matrix was used to examine the assumptions of multivariate normal distribution of the continuous variables (Figure 3).

Figure 3

Multivariate Normality/Linearity Scatter Diagram Matrix

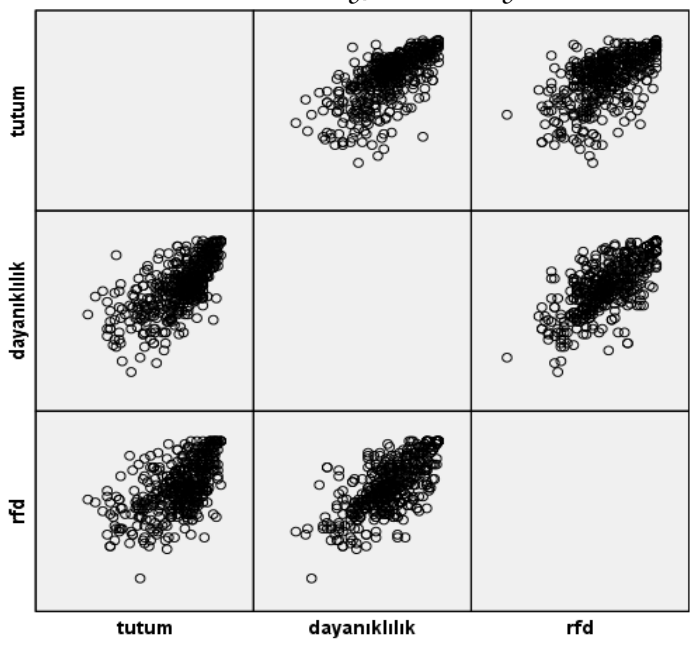

If the appearance of the diagrams formed by the variable pairs in the matrix is close to the shape of an ellipse, it is accepted that multivariate normality is achieved (Çokluk et al., 2016, p. 31). When the diagram in Figure 1 is examined, the multivariate normality assumption is also provided.

A correlation analysis was performed using the SPSS 24 program to determine the relationship between variables in the analysis of the data. A correlation coefficient between ".30 and .70" as the absolute value indicates a medium-level relationship between variables, and a high level of relationship between ".70 and 1.00" (Büyüköztürk, 2014, p. 32). Then, the mediating effect of the occupational resilience belief on the effect of the attitude toward the teaching profession on extrarole behaviors was examined. The SPSS PROCESS macro was used to test this hypothesis model. The PROCESS macro developed by Hayes (2009) for SPSS does analysis with Bootstrap sampling. The Bootstrap method (Hayes, 2009; MacKinnon et al., 2004), which has become widely used in calculating the mediation effect, is a resampling method. It is stated that the confidence intervals obtained for indirect effects with this method produce more accurate results than the confidence intervals obtained using a single sample (MacKinnon et al., 2004). The indirect effect Bootstrap confidence intervals should (be meaningful) not contain a value of 0 (zero) in the analysis performed with the Bootstrap sampling method in order to refer to the mediator effect (Gürbüz, 2019). Also, the full standardized effect size of the indirect effect being close to .01 indicates low effect, .09 indicates medium effect, and .25 displays high effect (Preacher \& Kelley, 2011). In this study, the mediator effect model tested with the SPSS PROCESS macro was also examined with the Sobel test, and the consistency of the result was confirmed. The Sobel test is another test that measures whether the mediator variable is statistically significant (Sobel, 1982).

After testing the mediator effect model, a moderated mediation effect analysis was performed using the SPSS PROCESS macro. Thus, the changes in the indirect effect according to the program and class level variables were examined. If the $W$ variable that regulates the indirect effect in the PROCESS macro is a categorical variable with more than two subgroups, it is compared by creating an indirect effect matrix system in the subgroups. In this context, the appropriate multicategorical matrix option should be preferred (Hayes, 2018). These matrix options make it easy to determine whether the mediating effect differs depending on a moderating effect and to examine which groups have a significant difference. In the scope of the study, both variables $(\mathrm{W} 1=$ 
program and $\mathrm{W} 2$ = class level), which were examined for the moderating role they play in the indirect effect, are categorical and consist of four subgroups. The categories for pre-service teachers' programs were coded as mathematics education (A), Turkish education (B), PCG (C), and classroom education (D). The categories of the pre-service teachers' educational class level were coded as: freshmen $(E)$, sophomores $(F)$, juniors $(G)$, and seniors $(H)$. The "indicator" multicategorical matrix was used to examine the change of indirect impact according to these subgroups. The indirect effect value in the subgroup determined as fixed in the indicator matrix was compared in pairs with the indirect effect values in all other subgroups. In this comparison made via Bootstrap, the results of the Bootstrap test for paired comparisons should be meaningful (confidence intervals should not contain 0 (zero)) in order to discuss the moderated mediator effect (Gürbüz, 2019).

\section{Results}

\subsection{The Relationships among the Study Variables}

In line with the first hypothesis of the research, the results obtained regarding the relationships between pre-service teachers' attitudes toward the teaching profession, their occupational resilience beliefs, and extra-role behaviors are presented in Table 1.

Table 1

Descriptive Statistics and Correlation Analysis Results

\begin{tabular}{llcccccc} 
& & \multicolumn{3}{c}{ Correlation } & \multicolumn{3}{c}{ Descriptive Statistics } \\
\cline { 2 - 7 } & 1 & 2 & 3 & $n$ & Mean & SD \\
\hline 1 & Attitudes toward the teaching & - & & & 430 & 4.19 & .541 \\
& profession & & & & 430 & 4.02 & .559 \\
2 & Occupational resilience belief & $.67^{* *}$ & - & & 430 & 4.03 & .561 \\
3 Extra-role behaviors & $.58^{* *}$ & $.69^{* *}$ & - & &
\end{tabular}

Table 1 revealed a positive and significant relationship between the attitude toward the teaching profession and occupational resilience belief $(r=.67, p<.01)$ and extra-role behaviors $(r=.58, p<.01)$. Accordingly, it is understood that the strength of the relationship between the attitude toward the teaching profession and the occupational resilience belief and extra-role behaviors is at a moderate level. At the same time, it was determined that there is a positive, significant, and moderate relationship between extra-role behaviors and the occupational resilience belief $(r=.69, p<.01)$. It can be said that there is a significant and positive relationship between all variables. In this regard, the first hypothesis of the research was accepted.

\subsection{Mediating Role of Occupational Resilience Beliefs in the Relationship between Attitudes toward the Teaching Profession and Extra-role Behaviors}

In line with the second hypothesis of the study, the mediating role of pre-service teachers' occupational resilience beliefs in the relationship between their attitudes toward the teaching profession and their extra-role behaviors was examined. In this regard, the total effect of preservice teachers' attitudes toward the teaching profession $(\mathrm{x})$ on their extra-role behaviors $(\mathrm{y})$ was calculated in the first stage (Figure 4). The second stage analyzed the mediating role of the occupational resilience beliefs in the effect of pre-service teachers' attitudes toward the teaching profession on their extra-role behaviors (Table 2). 
Figure 4

The Total Effect of Pre-service Teachers' Attitudes Toward the Teaching Profession on Their Extra-Role Behaviors

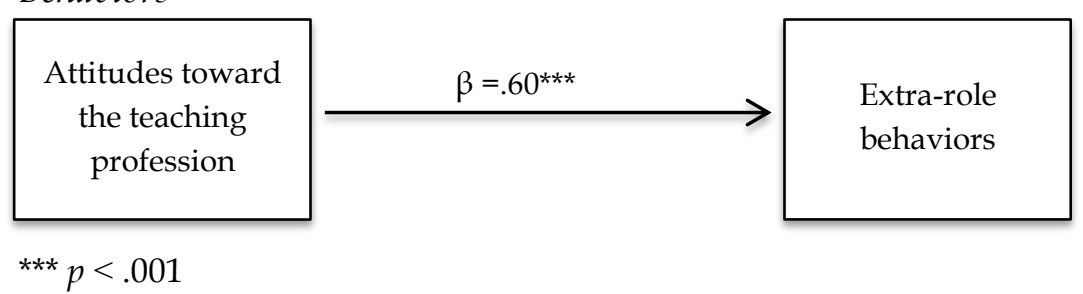

According to Figure 4, the total effect of pre-service teachers' attitudes toward the teaching profession on their extra-role behaviors is significant $(\beta=.60, \mathrm{SH}=.04, \mathrm{CI}=[.52, .68])$. The findings obtained when the mediator variable (occupational resilience belief) entered the model is presented in Table 2.

Table 2

The Mediating Role of Pre-service Teachers' Occupational Resilience Beliefs in the Effect of Their Attitudes Toward the Teaching Profession on Their Extra-role Behaviors

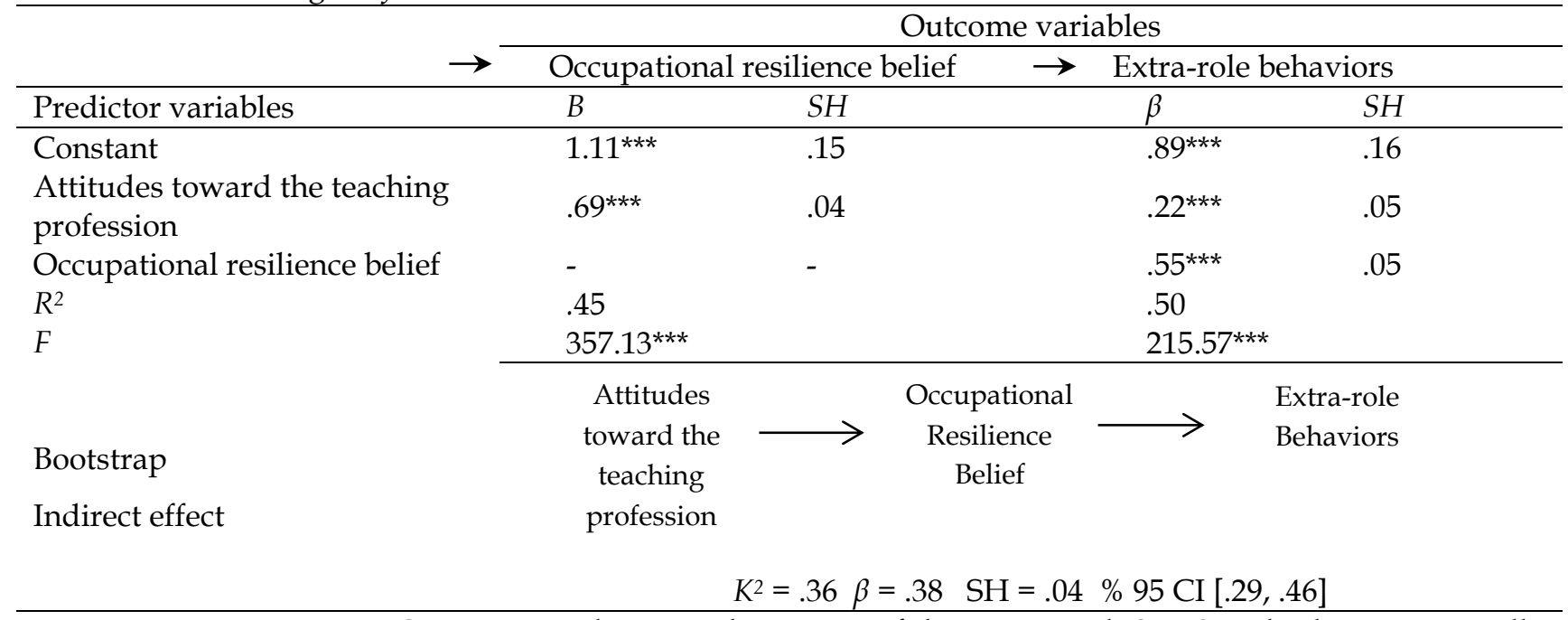

Not. ${ }^{* * *} p<.001 ; n=430$; CI: Bootstrap lower and upper confidence interval. SH: Standard error. $K^{2}$ : Fully standardized effect size. Bootstrap resampling $=5000$. Non-standardized beta coefficients $(\beta)$ were reported.

Table 2 shows that the effect of the attitude toward the teaching profession on the occupational resilience belief determined as the mediator variable was significant $(\beta=.69$, $\mathrm{CI}=[.62, .76], \mathrm{SH}=.04)$. Additionally, the effect of pre-service teachers' occupational resilience belief on their extra-role behaviors is also significant $(\beta=.55, \mathrm{CI}=[.45, .63], \mathrm{SH}=.05)$. However, when the occupational resilience belief, which was chosen as the mediator variable, was examined, it was determined that the effect of the attitude toward the teaching profession on extra-role behaviors weakened $(\beta=.22, \mathrm{CI}=[.12, .31], \mathrm{SH}=.05)$. In addition, it was determined that the indirect effect of the attitude toward the teaching profession on extra-role behaviors through the occupational resilience belief was significant $(\beta=.38 ; \mathrm{CI}=[.29, .46], \mathrm{SH}=.04)$. This situation reveals that the mediator effect model tested is statistically significant. At the same time, the full standardized indirect effect size $\left(K^{2}\right)$ of pre-service teachers' attitudes toward the profession on their extra-role behaviors was determined as ".36." In this respect, it can be said that the mediator effect in the tested model is high. In addition, as a result of the Sobel test, the existence of the mediator effect was confirmed (Sobel $\mathrm{z}=9.27, \mathrm{SH}=.04, p<.001$ ). In line with the findings obtained, the second hypothesis of the research was accepted. The confirmed mediator effect model is presented in Figure 5. 
Figure 5

Mediator Effect Model

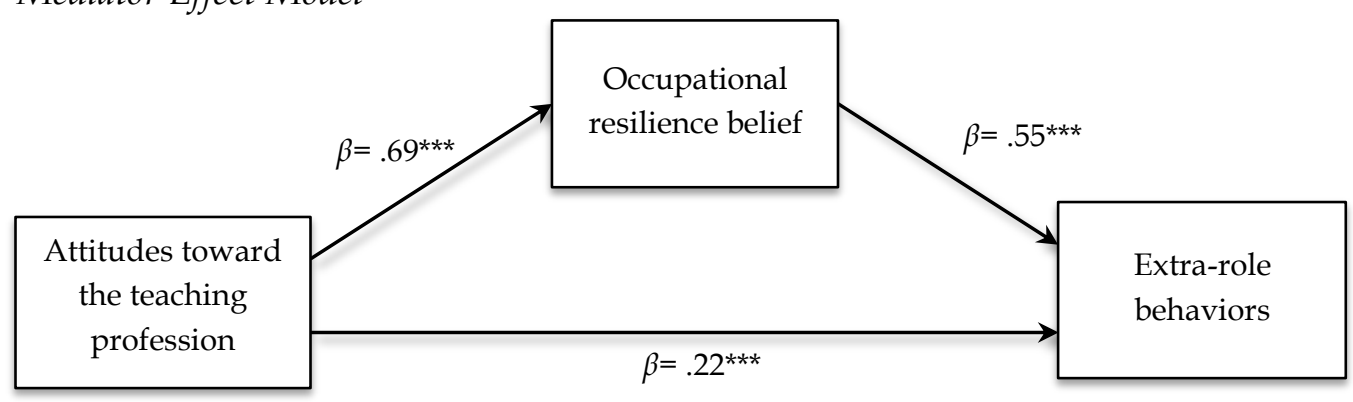

$* * * p<.001$

\subsection{The Moderated Mediating Role of the Occupational Resilience Belief in the Relationship Between Attitudes Toward the Teaching Profession and Extra-role Behaviors}

In the context of third hypothesis of the study (a), we tested whether the indirect effect of preservice teachers' attitudes toward the teaching profession $(X)$ on their extra-role behaviors $(Y)$ through the mediator variable (occupational resilience, $M$ ) depends on the program type variable $(W)$. Analysis results regarding the moderated mediator effect are presented in Table 3.

Table 3

Findings Regarding the Moderated Mediation Model Formed with the Program Variable

\begin{tabular}{|c|c|c|c|c|}
\hline \multirow{2}{*}{ Variables } & & \multicolumn{3}{|c|}{$\longrightarrow$ Extra-role behaviors } \\
\hline & & $\beta$ & LLCI & ULCI \\
\hline $\begin{array}{l}\text { Attitudes toward the teaching } \\
\text { profession }\end{array}$ & & $.19^{* * *}$ & .10 & .29 \\
\hline Occupational resilience belief & & $.66^{* * *}$ & .49 & .82 \\
\hline \multirow{3}{*}{ Program type $* * * *$} & A-B & $.21^{* * *}$ & .10 & .33 \\
\hline & $\mathrm{A}-\mathrm{C}$ & .03 & -.07 & .14 \\
\hline & A-D & $.15^{\star *}$ & .04 & .25 \\
\hline \multirow{3}{*}{$\mathrm{M} * \mathrm{~W}$ (Interaction) } & $\mathrm{M}^{*} \mathrm{~A}-\mathrm{B}$ & $-.26^{*}$ & -.47 & -.06 \\
\hline & $\mathrm{M}^{*} \mathrm{~A}-\mathrm{C}$ & -.09 & -.28 & .10 \\
\hline & $M^{*} \mathrm{~A}-\mathrm{D}$ & -.07 & -.28 & .15 \\
\hline$R^{2}$ & & & .53 & \\
\hline
\end{tabular}

The indirect effect of $\mathrm{X}$ on $\mathrm{Y}$ through $\mathrm{M}$ according to the program type variable

(A) Mathematics education

\begin{tabular}{ccc}
$\beta$ & LLCI & ULCI \\
\hline .46 & .33 & .59 \\
.27 & .16 & .41 \\
.39 & .29 & .51 \\
.41 & .31 & .52 \\
\hline
\end{tabular}

(B) Turkish education

diation index

(D) Classroom education

Moderated mediat

\section{A-B}

A-C

A-D $\beta$

$-.06$

$-.05$

-18
-.06
-05

Note. ${ }^{*} p<.05 ;{ }^{* *} p<.01 ;{ }^{* * *} p<.001 ;{ }^{* * * *}$ indicator matrix application, $n=430$; LLCI = Lower confidence interval; ULCI $=$ Upper confidence interval. Bootstrap resampling $=5000$. Non-standardized beta coefficients $(\beta)$ were reported.

According to Table 3, when the indirect effect of the attitude toward the teaching profession on the extra-role behaviors through the mediator variable (occupational resilience) was examined separately according to the program type variable, it was determined that the indirect effect was significant in all categories (A, B, C, and D). The highest indirect effect value was obtained from the mathematics education program $(\beta=.46, \mathrm{CI}[.33, .59])$. For other programs, the indirect effect 
value from high to low, respectively, was as follows: The categories of "Classroom education" $\beta=$ $.41, \mathrm{CI}[.31, .52])$, "PCG" $(\beta=.39$, CI $[.29, .51])$, and "Turkish education" $(\beta=.27, \mathrm{CI}[.16, .41])$ were determined. An indicator matrix application was performed to determine whether this change of indirect effect value between categories was meaningful. It was examined whether there is a significant difference between the indirect effect values by comparing category A (mathematics education), which was determined as the constant in the categories related to the program variable and has the highest indirect effect, and all other categories. No statistically significant difference was found between the indirect effect values in category $A$ and categories $\mathrm{C}$ and $\mathrm{D}$ (For A-C: $\beta=-.06$, CI $[-.19, .07]$; for A-D: $\beta=-.05$, CI $[-.18, .09])$. However, a significant difference was found in the comparison between the indirect effect values of category A and category B (For A-B: $\beta=-.18$, CI $[-.34,-.02])$. That is to say, the indirect effect of the attitude toward the teaching profession on extra-role behaviors through the occupational resilience belief varies according to the program. While this indirect effect is achieved at the best level in pre-service teachers in the mathematics education (A) program, the indirect effect significantly decreases statistically in the pre-service teachers in the Turkish education (B) program. In this context, it is understood that the program variable has a moderator effect on the indirect effect. In other words, the third hypothesis (a) of the research was accepted.

In line with the third hypothesis of the study (b), as another moderated mediator effect model, we examined whether the indirect effect of pre-service teachers' attitudes toward the teaching profession $(X)$ on extra-role behaviors $(Y)$ through the mediator variable (occupational resilience, $\mathrm{M})$ depends on the class level variable $(\mathrm{W})$. The findings obtained are presented in Table 4.

Table 4

Findings Regarding the Moderated Mediation Model Formed with the Class Level Variable

\begin{tabular}{|c|c|c|c|c|}
\hline \multirow{2}{*}{\multicolumn{2}{|c|}{ Variables }} & \multicolumn{3}{|c|}{ Extra-role behaviors } \\
\hline & & $\beta$ & LLCI & ULCI \\
\hline $\begin{array}{l}\text { Attitudes toward the teaching } \\
\text { profession }\end{array}$ & & $.23^{* * *}$ & .14 & .33 \\
\hline Occupational resilience belief & & $.54^{* * *}$ & .41 & .68 \\
\hline \multirow{3}{*}{ Class level $* * * *$} & A-B & .02 & .10 & .33 \\
\hline & $\mathrm{A}-\mathrm{C}$ & -.02 & -.13 & .08 \\
\hline & A-D & -.07 & -.18 & .03 \\
\hline \multirow{3}{*}{$\mathrm{M} * \mathrm{~W}$ (Interaction) } & $\mathrm{M}^{*} \mathrm{~A}-\mathrm{B}$ & -.09 & -.09 & .27 \\
\hline & $\mathrm{M}^{*} \mathrm{~A}-\mathrm{C}$ & -.08 & -.28 & .12 \\
\hline & $M^{*} A-D$ & -.03 & -.22 & .16 \\
\hline \multirow[t]{3}{*}{$R^{2}$} & & & .53 & \\
\hline & fect of $X$ & 1 accord & e class 1 & ble \\
\hline & & $\beta$ & LLCI & ULCI \\
\hline (E) Freshmen & & .38 & .26 & .51 \\
\hline (F) Sophomores & & .44 & .34 & .55 \\
\hline (G) Juniors & & .32 & .17 & .48 \\
\hline \multirow[t]{3}{*}{ (H) Seniors } & & .36 & .25 & .47 \\
\hline & \multicolumn{3}{|c|}{ Moderated mediation index } & \\
\hline & & $\beta$ & LLCI & ULCI \\
\hline A-B & & .06 & -.06 & .19 \\
\hline$A-C$ & & -.06 & -.23 & .12 \\
\hline A-D & & -.02 & -.15 & .11 \\
\hline
\end{tabular}

Note. ${ }^{* * *} p<.001$; ${ }^{* * * *}$ indicator matrix application, $n=430$; LLCI $=$ Lower confidence interval; ULCI = Upper confidence interval. Bootstrap resampling $=5000$. Non-standardized beta coefficients $(\beta)$ were reported.

According to Table 4, the indirect effect of pre-service teachers' attitude toward the teaching profession on their extra-role behaviors through the mediator variable (occupational resilience) was examined separately according to the class level of the candidates, and it was determined that 
the indirect effect was significant in all categories (E, F, G, and H). However, no statistically significant difference was found between the indirect effect values in these categories (For E-F: $\beta=.06, \mathrm{CI}[-.06, .19]$; for $\mathrm{E}-\mathrm{G} \beta=-.06, \mathrm{CI}[-.23, .12]$; for $\mathrm{E}-\mathrm{H} \beta=-.02$, CI $[-.15, .11])$. In other words, the indirect effect of pre-service teachers' attitudes toward the teaching profession on extrarole behaviors through their occupational resilience belief does not change according to the class level. Therefore, the third hypothesis (b) of the research was not accepted.

\section{Discussion and Conclusion}

This study determined that the occupational resilience beliefs of pre-service teachers played a mediating role in the relationship between the candidates' attitudes toward the teaching profession and their tendency to engage in extra-role behaviors. Additionally, the intensity of the indirect effect on extra-role behaviors showed a significant difference according to the type of program the pre-service teachers attended.

According to the results of the first hypothesis of the study, a positive and significant relationship was found between the attitude toward the teaching profession, occupational resilience belief, and extra-role behaviors. When the relationships between the variables are considered separately, there was a positive and significant relationship between the pre-service teachers' attitudes toward the teaching profession and their resilience beliefs, their attitudes toward the teaching profession and extra-role behaviors, and their occupational resilience beliefs and extra-role behaviors. This situation is similar to the findings of previous studies (Hussain et al., 2011; Knight, 2007). In addition, positive psychologists have focused on this issue in their studies, thinking that individuals' attitudes may be related to their beliefs and productivity (Woolfolk-Hoy et al., 2008).

Findings obtained in line with the second hypothesis of the research showed that the attitudes of pre-service teachers toward the teaching profession significantly determine their tendency to engage in extra-role behaviors. As the pre-service teachers' attitudes toward the teaching profession increase, their tendency to perform extra-role behaviors also increases, or as their attitudes toward the teaching profession decrease, their tendency to perform extra-role behaviors also decreases. It has been observed that the attitude toward the teaching profession shapes professional roles and behaviors (Oplatka \& Golan, 2011; Üstüner, 2006). Similarly, Bozali (2017) revealed that teachers' professional self-esteem predicted their tendency to engage in extra-role behaviors.

According to the analyses conducted to examine the indirect effect, it was determined that occupational resilience beliefs played a mediating role in the effect of pre-service teachers' attitudes toward the teaching profession on extra-role behaviors. In line with the findings, for teachers' attitudes toward the teaching profession to enhance their tendency to engage in extrarole behaviors, there is an additional need for the pre-service teacher's occupational resilience belief.

When examining the pre-service teachers' occupational resilience belief (when the mediator effect in the model is removed), the candidates' attitudes toward the teaching profession affect their tendency to engage in extra-role behaviors less. For this reason, to increase pre-service teachers' tendency to perform extra-role behaviors, it is necessary to increase their occupational resilience beliefs together with their attitudes toward the teaching profession. According to the mediator effect model determined, a positive attitude toward the teaching profession increases the occupational resilience belief, and the occupational resilience belief increases the tendency to engage in extra-role behaviors. In the studies conducted, it was determined that a positive attitude toward the teaching profession increases the occupational resilience belief (Dönmez \& Karasulu Kavuncuoğlu, 2019) and individuals with high occupational resilience beliefs fulfill their duties and responsibilities more (Beltman et al., 2011; Knight, 2007; Maddi, 2002). In addition, Luthans (2002a) stated that among the factors that determine the tendency of an individual to exhibit 
positive organizational behavior in positive psychology, the belief in resilience is at the forefront. The literature supports the indirect effect put forth through the occupational resilience belief.

As a result of the findings obtained in line with the third hypothesis of the study, it was first examined whether the intensity of the indirect effect (the effect of attitude on extra-role behaviors through occupational resilience) varies according to the type of program the pre-service teachers are studying. According to the results obtained, it was determined that the indirect effect was valid for pre-service teachers in all teaching programs, but this effect's intensity varied according to the program type. It was determined that this indirect effect influence was mostly observed in preservice teachers studying in the mathematics education program. On the contrary, the intensity of this indirect effect weakens significantly for the pre-service teachers in the Turkish education program. To increase the tendency of pre-service mathematics education teachers for extra-role behaviors, there is more need for occupational resilience beliefs together with their positive attitudes toward the teaching profession. In pre-service Turkish education teachers, on the contrary, their positive attitudes toward the profession increase their tendency to perform extrarole behaviors, but there is less need for the mediating role of the occupational resilience belief in this effect. Every pre-service teacher who displays a positive attitude will tend to engage in extrarole behaviors. However, students generally see mathematics as a difficult and boring lesson (Kislenko et al., 2005). This situation may cause students to stay away from and be afraid of mathematics lessons (Ingram, 2015). In fact, both social and individual prejudice and anxiety toward the mathematics lesson are quite high compared to other lessons. Mathematics is a difficult discipline in terms of its learning and teaching process (Dowker et al., 2019; Noviyanti, 2019). For this reason, pre-service mathematics teachers should be motivated to develop their occupational resilience beliefs more than other programs to display extra-role behaviors in the design and execution of the learning and teaching process.

In line with the third hypothesis of the study, whether the indirect effect influence put forward changes according to the pre-service teachers' class level of was examined. According to the findings, it was concluded that the indirect effect of pre-service teachers' attitudes toward the teaching profession on their extra-role behaviors through their occupational resilience belief did not change according to class level. It is understood that the structural model put forward is effective at every class level. Thus, it can be said that the activities to be carried out in line with the mediator effect model discussed in the study can be conducted at every class level to increase the pre-service teachers' tendency to perform extra-role behaviors.

\section{Suggestions}

Considering the results obtained in this study, the following suggestions are recommended:

> As positive attitudes toward the teaching profession are related to occupational resilience beliefs and extra-role behaviors, the learning experiences of pre-service teachers should be arranged in a way to prompt positive attitudes toward the teaching profession.

$>$ The proposed mediator effect model suggests that if pre-service teachers are given vocational training that will increase their positive attitudes toward the teaching profession, the candidates' occupational resilience belief and thus their extra-role behaviors will increase. For this reason, a formation process that will increase the positive attitudes toward the teaching profession should be designed in order to increase the pre-service teachers' tendency to engage in extra-role behaviors. The most important factor in this process is to include themes that emphasize occupational resilience in activities to increase the positive attitude toward the teaching profession.

$>$ Activities that demonstrate the significance of working in the teaching profession in the best way in challenging environmental conditions, different socio-cultural and socioeconomic environments, and motivate candidates can be designed. 
By determining teachers who have a positive attitude and high occupational resilience toward the teaching profession, guidance training can be conducted in groups consisting of these teachers and pre-service teachers.

$>$ The reason for the indirect effect (the effect of attitude on extra-role behaviors through occupational resilience) changing according to teaching programs can be addressed in new studies.

$>$ By designing new moderated mediation and moderation models for extra-role behaviors, relationships between variables can be revealed.

Funding sources. This research has not received a specific grant from funding organizations in the public, commercial, or nonprofit sectors.

\section{References}

Abshir, B. A. (2020). Somali secondary school students' attitudes towards the teaching profession. Academic Research International, 11(2), 30-40.

Ajzen, I., \& Cote, N. G. (2008). Attitudes and the prediction of behavior. In W. D. Crano \& R. Prislin (Eds.), Attitudes and attitude change (pp. 289-311). Psychology.

Akbaşlı, S. (2009). Öğretmenlik mesleğinin özellikleri, eğitim sisteminde öğretmen yetiştirmenin rolü [Characteristics of the teaching profession, the role of teacher training in the education system]. In K. Kıroğlu \& C. Elma (Eds.), Eğitim bilimine giriş [Introduction to educational science] (pp. 276-317). Pegem Academy.

Aktan, C. C. (2015). A civic duty, ethical resistance and conscientious objection behaviour against organizational wrongdoings: WHISTLEBLOWING. Journal of Organization and Management Sciences, 10, 113.

Ayık, A., \& Ataş, Ö. (2014). The relationship between pre-service teachers' attitudes towards the teaching profession and their motivation to teach. Journal of Educational Sciences Research, 4(1), 25-43.

Beltman, S., Mansfield, C., \& Price, C. (2011). Thriving not just surviving: A review of research on teacher resilience. Educational Research Review, 6, 185-207. https://doi.org/10.1016/j.edurev.2011.09.001

Blazar, D. (2018). Validating teacher effects on students' attitudes and behaviors: Evidence from random assignment of teachers to students. Education Finance and Policy, 13(3), 281-309. https://doi.org/10.1162/edfp_a_00251

Bowles, T., \& Arnup, J. L. (2016). Early career teachers' resilience and positive adaptive change capabilities. The Australian Educational Researcher, 43(2), 147-164. https:/ / doi.org/10.1007/s13384-015-0192-1

Bozali, S. (2017). The role of vocational self-esteem and extra role behaviours to explain the level of zest for work of preschool teachers (Publication No. 470515) [Master's thesis, Recep Tayyip Erdoğan UniversityRize]. Council of Higher Education Thesis Center.

Brown, T. A. (2006). Confirmatory factor analysis for applied research. Guilford.

Büyüköztürk, Ş. (2014). Sosyal bilimler için veri analizi el kitabı [Guide book of data analysis for social sciences] (19nd ed.). Pegem Academy.

Chakraborty, A., \& Mondal, B. C. (2014). Attitude of prospective teachers towards teaching profession. American Journal of Social Sciences, 2(6), 120-125.

Coşkun, M. K. (2011). The attitudes of candidates of religious culture teachers directed towards teaching profession: A comparison of divinity and education. EKEV Akademi Dergisi, 15(48), 269-279

Çapri, B., \& Çelikkaleli, Ö. (2008). Investigation of preservice teachers? Attitudes towards teaching and professional self efficacy beliefs according to their gender programs and faculties. Inonu University Journal of the Faculty of Education, 9(15), 33-53.

Çeliköz, N., \& Çetin, F. (2004). Anadolu öğretmen lisesi öğrencilerinin öğretmenlik mesleğine yönelik tutumlarını etkileyen etmenler [Factors affecting anatolian teaching high school students' attitudes to the teaching profession]. National Education Journal, 162(1), 139-157.

Çokluk, Ö., Şekercioğlu, G., \& Büyüköztürk, Ş. (2016). Sosyal bilimler için çok değişkenli istatistik SPSS ve LISREL uygulamalar [SPSS and LISREL applications for multivariate statistics for social sciences] (4nd ed.). Pegem Academy.

Demirel, Ö., \& Ün, K. (1987). Eğitim terimleri [Educational terms]. Şafak.

Demirel, Ö. (2003). Dictionary of education (2nd ed.). Pegem Academy. 
Dowker, A., Cheriton, O., Horton, R., \& Mark, W. (2019). Relationships between attitudes and performance in young children's mathematics. Educational Studies in Mathematics, 100(3), 211-230. https:// doi.org/10.1007/s10649-019-9880-5

Dönmez, Ö., \& Karasulu Kavuncuoğlu, M. (2019). An examination of the relationship among the occupational resilience beliefs, attitudes toward teaching, and professional self-respect of pre-service early childhood education teachers. Basic Education, 1(1), 48-59.

Gable, S. L., \& Haidt, J. (2005). What (and why) is positive psychology? Review of General Psychology, 9, (2) 103-110. https://doi.org/10.1037/1089-2680.9.2.103

Gunzler, D., Chen, T., Wu, P., \& Zhang, H. (2013). Introduction to mediation analysis with structural equation modeling. Shanghai Archives of Psychiatry, 25(6), 390-394. https://dx.doi.org/10.3969/j.issn.10020829.2013.06.009

Güner Demir, T. (2015). Teachers' extra role behavior and its relationship with personal values (Publication No. 381791) [Master's thesis, Ankara University-Ankara]. Council of Higher Education Thesis Center.

Gürbüz, S. (2019). Sosyal bilimlerde aracı, düzenleyici ve durumsal etki analizleri [Mediator, moderator and conditional analyzes in social sciences]. Seçkin.

Hayes, A. F. (2009). Beyond Baron and Kenny: Statistical mediation analysis in the new millennium. Communication Monographs, 76(4), 408-420. https://doi.org/10.1080/03637750903310360

Hayes, A. F. (2018). Introduction to mediation, moderation, and conditional process analysis second edition: A regression-based approach (2nd ed.). Guilford.

Hooper, D., Coughlan, J., \& Mullen, M. R. (2008). Structural equation modelling: Guidelines for determining model fit. Electronic Journal of Business and Research Methods, 6, 53-60.

Hussain, S., Ali, R., Khan, M. S., Ramzan, M., \& Qadeer, M. Z. (2011). Attitude of secondary school teachers towards teaching profession. International Journal of Academic Research, 3(1), 985-990.

Ingram, N. (2015). Students' relationships with mathematics: Affect and identity. In M. Marshman, V. Geiger \& A. Bennison (Eds.), Mathematics education in the margins (Proceedings of the 38th annual conference of the Mathematics Education Research Group of Australasia) (pp. 301-308). MERGA.

Jahan, H. (2017). A Study of professional attitude in upper primary school teachers. The International Journal of Indian Psychology, 5(1), 179-191. https://doi.org/10.25215/0501.080

Kalmaz, M., \& Tozkoparan, G. (2020). Impact of psychological ownership on the extra role behavior of employees: A research in private sector. İzmir Journal of Economics, 35(2), 255-270.

Karasar, N. (2016). Bilimsel araştırma yöntemi [Scientific research method] (30nd ed.). Nobel.

Katz, D., \& Kahn R. L. (1977). Örgütlerin toplumsal psikolojisi [Social psychology of organizations] (H. Can \& Y. Bayar, Trans.). Doğan. (Original work published in 1966)

Kislenko, K., Grevholm, B., \& Lepik, M. (2005, September 2-6). Mathematics is important but boring: Students' beliefs and attitudes towards mathematics [Paper presentation]. 4th Nordic Conference on Mathematics Education, Trondheim, Norway.

Knight, C. (2007). A resilience framework: Perspectives for educators. Health Education, 107 (6), 543-555.

Luthans, F. (2002a). Positive organizational behavior: Developing and managing psychological strengths. Academy of Management Executive, 16(1), 57-72. https://doi.org/10.5465/ame.2002.6640181

Luthans, F. (2002b). The need for and meaning of positive organizational behavior. Journal of Organizational Behavior, 23, 695-706. https://doi.org/10.1002/job.165

MacKinnon, D. P., Lockwood C. M., \& Williams, J. (2004). Confidence limits for the indirect effect: Distribution of the product and resampling methods. Multivariate Behavioral Research, 39(1), 99-128.

Maddi, S. R. (2002). The story of hardiness: Twenty years of theoring, research, and practice. Consulting Psychology Journal, 54, 173-185. https:// doi.org/10.1037/1061-4087.54.3.173

Maddi, S. R., Harvey, R. H., Khoshaba, D. M., Fazel, M., \& Resurreccion, N. (2009). The personality construct of hardiness, IV expressed in positive cognitions and emotions concerning oneself and developmentally relevant activities. Journal of Humanistic Psychology, 49(3), 292-305. https:// doi.org/10.1177/0022167809331860

Malcom, L. A. C. (2007). Beginning teachers, resilience and retention [Doctoral Dissertation, Texas State University]. Digital Library of Texas State University.

Mazana, Y. M., Suero Montero, C., \& Olifage, C. R. (2019). Investigating students' attitude towards learning mathematics. International Electronic Journal of Mathematics Education, 14(1), 207-231. http://dx.doi.org/10.29333/iejme/3997

Melki, H., \& Bouzid, M. S. (2021). What physical education trainees think about teaching profession and mentoring during a TVET practical traineeship? Journal of Technical Education and Training, 13(2), 34-43. 
Morris, C. G. (2002). Psikolojiyi anlamak [Understanding psychology] (H. B. Ayvaşık \& M. Sayıl, Trans. Eds.). Turkish Psychological Association. (Original work published 1995)

Noviyanti, M. (2019). Teachers' belief in mathematics teaching: A case study of early childhood education teachers. Journal of Physics: Conference Series, 1315, 012010. https://dx.doi.org/10.1088/17426596/1315/1/012010

Oplatka, I., \& Golan, R. (2011). The teacher's extra-role behaviors: Some illuminations from a study of the Israeli religious state education system. Religious Education, 106(5), 516-536.

Preacher, K. J., \& Kelley, K. (2011). Effect size measures for mediation models: Quantitative strategies for communicating indirect effects. Psychological methods, 16(2), 93-115.

Robbins, S. P., \& Judge, T. A. (2012). Örgütsel davranış [Organizational behavior] (İ. Erdem, Trans.; 14th ed.). Nobel. (Original work published 2006)

Runhaar, P., Konermann, J., \& Sanders, K. (2013). Teachers' organizational citizenship behaviour: Considering the roles of their work engagement, autonomy and leader-member exchange. Teaching and Teacher Education, 30, 99-108.

Sezgin, F., \& Ada, K. (2018, November 1-4). Academic, social and personality traits of teachers with high level of psychological hardiness [Paper Presentation]. 9th International Education Management Forum, Antalya, Turkey.

Sobel, M. E. (1982). Asymptotic confidence intervals for indirect effects in structural equation models. Sociological Methodology, 13, 290-312. https:// doi.org/10.2307/270723

Somech, A., \& Ron, I. (2007). Promoting organizational citizenship behavior in schools: The impact of individual and organizational characteristics. Educational Administration Quarterly, 43(1), 38-66. https://doi.org/10.1177/0013161X06291254

Srivastava, A. P., Babu, V., \& Shetye, S. K. (2019). Exploring students' learning efficacy: Predicting role of teachers' extra role behaviour and art-based innovation pedagogies. European Journal of Training and Development, 43(9), 842-859. http:/ / dx.doi.org/10.1108/EJTD-04-2019-0050

Sümer, N. (2000). Structural equation modeling: Basic concepts and applications. Turkish Psychology Writings, $3(6), 49-74$.

Tabachnick, B. G., \& Fidell, L. S. (2001). Using multivariate statistics (4nd ed.). Allyn \& Bacon.

Tagay, Ö., \& Demir, K. (2016). Development of occupational resilience beliefs scale for teacher candidates. Kastamonu Education Journal, 24(4), 1603-1620.

Tait, M. (2008). Resilience as a contributor to novice teacher success, commitment and retention. Teacher Education Quarterly, 35(4), 57-75.

Üstüner, M. (2006). Reliability and validity study of an attitude scale of teaching profession.

Educational Management in Theory and Practice, 45, 109-127.

Van Loon, N. M., Vandenabeele, W., \& Leisink, P. (2017). Clarifying the relationship between public service motivation and in-role and extra-role behaviors: The relative contributions of person-job and personorganization fit. The American Review of Public Administration, 47(6), 699713. https:// doi.org/10.1177\%2F0275074015617547

Woolfolk-Hoy, A., Hoy, W. K., \& Kurz, N. (2008). Teacher's academic optimism: The development and test of a new construct. Teaching and Teacher Education, 24, 821-834. https://doi.org/10.1016/j.tate.2007.08.004

Yang, K., \& Banamah, A. (2014). Quota sampling as an alternative to probability sampling? An experimental study. Sociological Research Online, 19(1), 56-66. 